\title{
Effect of transforming growth factor- $\beta 3$ on the expression of Smad3 and Smad7 in tenocytes
}

\author{
$\mathrm{KE} \mathrm{JIANG}^{1,2^{*}}$, GUO CHUN $^{3 *}$, ZIMING WANG $^{2}$, QUANYIN DU ${ }^{2}$, AIMIN WANG ${ }^{2}$ and YAN XIONG ${ }^{2}$ \\ ${ }^{1}$ Department of Orthopedics, Affiliated Hospital of North Sichuan Medical College, Nanchong, Sichuan 637000; \\ ${ }^{2}$ Department of Orthopedics, Daping Hospital, The Third Military Medical University, Chongqing 400042; \\ ${ }^{3}$ Department of Medicine, Luohe Medical College, Luohe, Henan 462002, P.R. China
}

Received March 7, 2015; Accepted January 5, 2016

DOI: $10.3892 / \mathrm{mmr} .2016 .4944$

\begin{abstract}
Tendon adhesion is a common problem in the healing of injured tendons. The molecular mechanisms of the TGF- $\beta$ /Smad signaling pathway have been determined, and the role of TGF- $\beta$ has been well characterized in wound healing. However, the intracellular mechanism or downstream signals by which TGF- $\beta 3$ modulates its effects on tendon healing have not been well elucidated. The aim of this study was to determine the effect of TGF- $\beta 3$ on the TGF- $\beta /$ Smad signaling pathway in tenocytes. Quantitative polymerase chain reaction and western blot analysis were used to analyze the effect of TGF- $\beta 3$ on the regulation of the expression of Smad proteins in tenocytes. The results demonstrated that TGF- $\beta 3$ has no significant effect on the proliferation of tendon cells. The addition of TGF- $\beta 3$ to tenocytes can significantly downregulate the expression of Smad3 and upregulate the expression of Smad7 at the gene and protein levels. The results demonstrate that TGF- $\beta 3$ may regulate $\mathrm{Smad} 3$ and $\mathrm{Smad} 7$ proteins through the TGF- $\beta$ /Smad signaling pathway to minimize extrinsic scarring. Thus, it may provide a novel approach to decrease tendon adhesion and promote tendon healing.
\end{abstract}

\section{Introduction}

One of the greatest challenges in tendon healing is adhesion formation, caused by tissue scarring around the injured tendon sheath, resulting in limited finger functions (1). Despite improvements in materials and surgical techniques, various pharmacological modalities and the evolution of rehabilitative

Correspondence to: Dr Yan Xiong, Department of Orthopedics, Daping Hospital, The Third Military Medical University, 10 Changjiang Branch Road, Yuzhong, Chongqing 400042, P.R. China

E-mail: xiongyan815@163.com

${ }^{*}$ Contributed equally

Key words: transforming growth factor- $\beta$, Smad, adhesion, tendon, cell signaling therapies, the postoperative outcome of flexor tendon healing remains limited by flexor tendon adhesion. In particular, peritendinous adhesion formation continues to present a problem. Tendon healing often causes disorganization of the extracellular matrix (ECM) and the formation of scar tissue predominantly composed of dense collagenous fibers. Healed tendons often have inferior mechanical properties compared with undamaged tendons. Therefore, restoration of function and structure of injured tendons is an important problem in hand surgery (2).

Injured tendon healing relies on the levels of growth factors and cytokines to ensure that cellular responses are mediated in an appropriate manner. Among the numerous growth factors involved, transforming growth factor $\beta$ (TGF- $\beta$ ) is suggested to be key in tendon healing. TGF- $\beta$ s are a family of a number of isoforms, which have multiple roles in tissue morphogenesis and cell proliferation (3). The TGF- $\beta$ isoforms have different effects during wound healing and scarring. TGF- $\beta 1$ is found at high levels in the wound microenvironment and promotes myofibroblast differentiation, production of ECM components and fibroblast chemotaxis. In addition, TGF- $\beta 1$ promotes the formation of scar tissue during adult wound healing. However, embryonic wound microenvironments contain low levels of TGF- $\beta 1$ and high levels of TGF- $\beta 3$ (4). Furthermore, the addition of exogenous TGF- $\beta 3$ to an adult wound promotes scar-free healing in rats (5), and injuries obtained in utero heal scar free, possibly due to the relatively high levels of TGF- $\beta 3$ compared with TGF- $\beta 1$. In addition, developmental research in chickens has shown that the TGF- $\beta 3$ isoform is existent throughout the morphogenesis of tendon tissue (6).

The role of TGF- $\beta$ in wound healing has been well demonstrated and numerous cellular and molecular mechanisms underlying the TGF- $\beta /$ Smad signaling pathway have been identified; however, the intracellular mechanisms and downstream signals of TGF- $\beta$ in wound healing are poorly understood. Targeting the inhibition of TGF- $\beta$ signaling pathway using therapeutic agents to reduce scarring and improve wound healing has been successful in pre-clinical studies $(7,8)$. Despite these studies, the intracellular mechanism and downstream signals by which TGF- $\beta 3$ adjusts these effects in healing tendons are poorly understood. A recent study has demonstrated that Smad proteins act as key 
transcription factors for the TGF- $\beta$ signaling pathway (9). There are three groups of Smad proteins: Receptor activated Smads, common mediator Smads and inhibitory Smads (10). $\mathrm{Smad} 3$ is a receptor activated Smad and is phosphorylated in response to TGF- $\beta$ signaling through the TGF- $\beta$ type I and TGF- $\beta$ type II transmembrane receptors (11). Once activated, Smad3 heterodimerizes with Smad4, which is a common mediator Smad, and translocates to the nucleus where Smad3 is hypothesized to modulate the transcription of genes involved in cell growth (12), inflammatory responses (13) and the formation of the ECM (14). Inhibitory Smad proteins, including Smad6 and Smad7, inhibit the phosphorylation of receptor Smad proteins via TGF- $\beta 3$ receptors, and prevent the association of receptor Smad proteins with Smad4.

The aim of this study was to determine the influence of TGF- $\beta 3$ in regulating the expression of Smad proteins in tenocytes, and to investigate the underlying TGF- $\beta / \mathrm{Smad}$ signaling pathway.

\section{Materials and methods}

Chemicals and reagents. TGF- $\beta 3$ was purchased from Abcam (Cambridge, UK). Trypsin-EDTA and Dulbecco's modified Eagle's medium (DMEM) were obtained from Gibco; Thermo Fisher Scientific Inc. (Waltham, MA, USA). 3-(4,5-dimethylthiazol-2-yl)-2,5-diphenyltetrazolium bromide (MTT) was purchased from Sigma-Aldrich (St. Louis, MO, USA) and fetal bovine serum (FBS) was purchased from HyClone (Logan, UT, USA). All other analytical grade chemicals were received from typical commercial sources in China.

Tenocyte culture. Tendon tissue was obtained under sterile conditions from the flexor tendon of New Zealand white rabbits ( $\mathrm{n}=3$; age, 12 weeks; weight, $2 \mathrm{~kg}$ ) obtained from the Experimental Animal Center of The Third Military Medical University (Chongqing, China). Animals were maintained in a room with a constant temperature $\left(22 \pm 1^{\circ} \mathrm{C}\right)$, relative humidity (40-60\%) with a $12 \mathrm{~h}$ light/dark cycle. The study was approved by the ethics Animal Health Trust Research Ethics Committee of The Third Military Medical University. Rabbits were sacrificed by anaesthetic injection of 3\% pentobarbital sodium ( $1 \mathrm{ml} / \mathrm{kg}$; Merck \& Co., Inc., Kenilworth, NJ, USA) and venous air embolism. Three experimental repeats were performed using one line of tendon cells from each animal. The tendon tissue was rinsed with phosphate-buffered saline (PBS) separately 3 times, cut into $1-\mathrm{mm}^{3}$ sections and then placed into sterile containers. The sections were transferred into $0.1 \%$ trypsin-DMEM. Mixtures were then placed on a shaker and digested by $0.1 \%$ trypsin-DMEM (Sigma-Aldrich) for $30 \mathrm{~min}$, followed by centrifugation at $44.72 \mathrm{x}$ g for $5 \mathrm{~min}$ at $4^{\circ} \mathrm{C}$. The supernatant was then discarded and the resulting cell pellets were resuspended in $0.1 \%$ collagenase II (Sigma-Aldrich) with DMEM containing $10 \% \mathrm{FBS}$ for $2 \mathrm{~h}$ at $37^{\circ} \mathrm{C}$. Tenocytes were then centrifuged at $44.72 \times \mathrm{g}$ for $5 \mathrm{~min}$ at $4^{\circ} \mathrm{C}$ and washed twice with Hank's Buffer solution (Sigma-Aldrich), and then filtered through a $70 \mu \mathrm{m}$ nylon sterile filter to remove debris. The samples were centrifuged at $44.72 \times \mathrm{g}$ for $5 \mathrm{~min}$ at $4^{\circ} \mathrm{C}$ to obtain tenocyte pellets and resuspended in a sterile culture bottle in $5 \mathrm{ml}$ DMEM/F12 containing $10 \% \mathrm{FBS}, 100 \mathrm{mg} / \mathrm{ml}$ streptomycin and $100 \mathrm{U} / \mathrm{ml}$ penicillin (Gibco; Thermo Fisher
Scientific, Inc.). Samples were kept at $37^{\circ} \mathrm{C}$ in an incubator (Heal Force Bio-meditech Holdings Ltd; Shanghai, China; $\mathrm{HF} 90, \mathrm{CO}_{2}$ Jacket Incubator) throughout the digestion process. Culture medium was checked and changed every third day until tenocytes were confluent $\left(2 \times 10^{6}\right.$ cells $\left./ \mathrm{cm}^{2}\right)$. Adherent tenocytes received short-term treatment with $0.25 \%$ trypsin in $0.2 \%$ EDTA. The growth of tenocytes was monitored under a microscope (Olympus 1X71; Olympus Corporation, Tokyo, Japan). Tenocytes were treated with, or without, TGF- $\beta 3$ (10 $\mathrm{ng} / \mathrm{ml})$ for 1,2,4,6 and $8 \mathrm{~h}$. To evaluate the effect of blocking intracellular protein and mRNA synthesis on the expression of Smad 7 and Smad3 induced by TGF- $\beta 3$, cycloheximide (CHX; Sigma-Aldrich) or actinomycin D (Sigma-Aldrich) were added to tenocytes $2 \mathrm{~h}$ prior to the addition of TGF- $\beta 3$ for $4 \mathrm{~h}$.

Immunohistochemistry assessment. Tenocytes were seeded onto sterile cover glass at a density of $2 \times 10^{6}$ cells $/ \mathrm{ml}$, and then incubated for 3 days. The cover glass was removed and washed with PBS. The tenocytes were fixed with $4 \%$ paraformaldehyde (Aladdin Reagent Co., Shanghai, China) for $20 \mathrm{~min}$ and washed 3 times for 2 min with PBS. Cells were then treated with $0.5 \%$ Triton X-100 (Aladdin Reagent Co.) for $20 \mathrm{~min}$ and washed with PBS 3 times for $2 \mathrm{~min}$. Then, $3 \% \mathrm{H}_{2} \mathrm{O}_{2}$ was applied for $30 \mathrm{~min}$ at room temperature, and washed with PBS 3 times for $2 \mathrm{~min}$. After blocking for at least $1 \mathrm{~h}$ at room temperature, tenocytes were incubated with 1:100 rabbit polyclonal anti-collagen I (bs-10423R) and rabbit polyclonal anti-collagen III primary antibodies (bs-0549R) (both purchased from Beijing Biosynthesis Biotechnology Co., Ltd., Beijing, China) at $4^{\circ} \mathrm{C}$ overnight and washed with PBS 3 times for $2 \mathrm{~min}$. Sections were then incubated with 1:100 horseradish peroxidase (HRP)-conjugated goat polyclonal anti-rabbit immunoglobulin G (IgG; bs-0295G-HRP; Beijing Biosynthesis Biotechnology Co., Ltd.) secondary antibody for at least $1 \mathrm{~h}$ at room temperature. The cover glass was washed with PBS three times for $10 \mathrm{~min}$. The signal was developed using a HRP-DAB detection kit (Beijing Biosynthesis Biotechnology Co., Ltd.) and washed with water, counterstained with Harris hematoxylin (Beijing Biosynthesis Biotechnology Co., Ltd.) and washed again. Immunoreactivity was then observed under a microscope (Olympus 1X71; Olympus Corporation). The negative control group was treated with PBS. All the steps were the same as in the positive control group.

Reverse transcription-quantitative polymerase chain reaction (RT-qPCR). Total RNA was isolated from the cultured tenocytes using TRIzol reagent (Invitrogen Life Technologies, Grand Island, NY, USA) and quantified using spectrophotometry at $260 \mathrm{~nm}$ (Eppendorf BioSpectrometer; Eppendorf AG, Hamburg, Germany). After isolation, $2 \mu \mathrm{g}$ total RNA was reverse transcribed using the HiFi-MMLV cDNA kit (Beijing CoWin Biotech Co. Ltd., Beijing, China) according to the manufacturer's protocol. The primer sequences for Smad3, Smad7 and glyceraldehyde 3-phosphate dehydrogenase (GAPDH) are shown in Table I. Primers were purchased from Shanghai Generay Biotech Co., Ltd. (Shanghai, China). According to the manufacturer's protocol, qPCR was performed with an SYBR Premix Ex Taq [Takara Biotechnology (Dalian) Co., Ltd., Dalian, China]. All qPCR reactions were performed using the ABI PRISM 7700 sequence detection system (Applied 
Table I. Sequences of primers used for reverse transcription-quantitative polymerase chain reaction.

\begin{tabular}{lll}
\hline Gene & \multicolumn{1}{c}{ Forward primer } & \multicolumn{1}{c}{ Reverse primer } \\
\hline Smad3 & AGGTCTTCGCAGAGTGCCTCA & GGGTCAACTGGTAGACAGCCTCA \\
Smad7 & CCATCACCTTAGCCGACTCTG & CCATCGGGTATCTGG-AGTAAGGA \\
GAPDH & GCACCGTCAAGGCTGAGAAC & TGGTGAAGACGCCAGTGGA
\end{tabular}

GAPDH, glyceraldehyde 3-phosphate dehyrogenase.

Biosystems, Grand Island, NY, USA). In each reaction, $1 \mu 1$ cDNA, $10 \mu$ l SYBR Premix Ex Taq (Takara Biotechnology Inc., Dalian, China), and $0.4 \mu \mathrm{M}$ forward and reverse primer in a total volume of $20 \mu \mathrm{l}$ were used. The reaction conditions were as follows: 1 cycle at $95^{\circ} \mathrm{C}$ for $30 \mathrm{sec}$ followed by 40 cycles at $95^{\circ} \mathrm{C}$ for $5 \mathrm{sec}$, and $60-66^{\circ} \mathrm{C}$ for $30 \mathrm{sec}$. qPCR for each sample was run in triplicate. $\beta$-actin was used as an internal control, and all results were analyzed using the standard $2^{-\Delta \Delta \mathrm{Cq}}$ method described previously (15).

Western blot analysis. At the end, tenocytes culture medium was aspirated and tenocytes were detached by scrapping in PBS. Detached cells were centrifuged at $21,000 \times \mathrm{g}$ at $4^{\circ} \mathrm{C}$ for $5 \mathrm{~min}$. Cell pellets were then lysed in $300 \mu \mathrm{l}$ lysis buffer (Cytobuster protein extraction reagent; Beijing Biosynthesis Biotechnology Co., Ltd.) with $1 \mathrm{mM} \mathrm{Na}_{3} \mathrm{VO}_{4}, 25 \mathrm{mM} \mathrm{NaF}$ and $1 \mathrm{X}$ protease inhibitor cocktail (Beijing Biosynthesis Biotechnology Co., Ltd.). Protein concentrations were quantified by spectrophotometry (Eppendorf BioSpectrometer, Eppendorf, Hamburg, Germany). For western blot analysis, equal quantities of protein were loaded onto $12 \%$ SDS-PAGE gels (Beijing Biosynthesis Biotechnology Co., Ltd.) and electrotransferred onto polyvinylidne difluoride (PVDF) membranes (Millipore, Bedford, MA, USA). The membranes were then blocked with $5 \%(\mathrm{w} / \mathrm{v})$ bovine serum albumin in TBST [10 mM Tris, $150 \mathrm{mM} \mathrm{NaCl}$, and $0.1 \%$ (v/v) Tween 20 , $\mathrm{pH}=7.5$ ] for $1 \mathrm{~h}$ at room temperature, and incubated with 1:500 rabbit polyclonal anti-Smad3 (sc-8332), anti-Smad7 (sc-11392), anti-p-Smad3 (sc-130218) and anti-GAPDH (sc-59540) primary antibodies overnight at $4^{\circ} \mathrm{C}$. The membranes were then incubated with 1:500 HRP-conjugated goat polyclonal anti-rabbit IgG (sc-2004) secondary antibody at room temperature for $2 \mathrm{~h}$ (Santa Cruz Biotechnology, Inc. Santa Cruz, CA, USA). Enhanced chemiluminescence (Beyotime Institute of Biotechnology, Shanghai, China) was used to observe immunoreactive protein signals. Protein signals were then visualized on films (Beijing Biosynthesis Biotechnology Co., Ltd.), and scanned and quantified using the Image J software (version 1.48; National Institutes of Health, Bethesda, MA, USA). For re-probing, PVDF membranes were stripped with $0.2 \mathrm{M} \mathrm{NaOH}$ for 10 min prior to blocking with another primary antibody. The expression of molecules of interest was determined relative to $\beta$-actin.

CHX and actinomycin D. CHX was added to block intracellular protein synthesis. In each group, $2 \mathrm{ml} \mathrm{CHX}(10 \mu \mathrm{g} / \mathrm{ml})$ was added to pre-process tenocytes $2 \mathrm{~h}$ prior to the addition of TGF- $\beta 3$. Actinomycin D was added to block intracellular

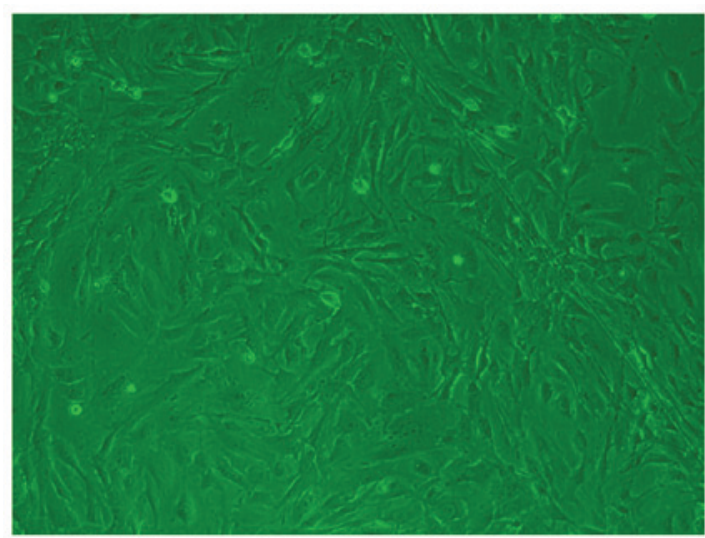

Figure 1. Tenocytes were spindle-shaped or multi-angle shaped.Magnification $\mathrm{x} 100$.

mRNA synthesis. In each group, $2 \mathrm{ml}$ actinomycin D (5 pg/ml) was added to pre-process tenocytes $2 \mathrm{~h}$ prior to the addition of TGF- $\beta 3$. Total RNA was isolated for RT-qPCR and statistical analysis as mentioned above.

Statistical analysis. Data are expressed as the mean \pm standard deviation for three or more independent experiments. Significant differences were determined using factorial analysis of variance. Statistical analysis was performed using SPSS 13.0 software (SPSS, Inc., Chicago, IL, USA). P<0.05 was considered to indicate a statistically significant difference.

\section{Results}

Tenocyte culture and immunohistochemistry assessment. Tenocytes were isolated and cultured, and following microscopic analysis were observed to be multi-angle shaped or spindle-shaped (Fig. 1). Immunohistochemical analysis was performed to distinguish between tenocytes and fibroblasts. Immunohistochemical assessment demonstrated that fibroblasts positively stained for collagen I, and stained negaitvely for collagen III (Fig. 2). This demonstrated that the cells were tenocytes.

$R T-q P C R$ and western blot analysis results. Tenocytes were treated with, or without TGF- $\beta 3(10 \mathrm{ng} / \mathrm{ml})$ for $1,2,4,6$ and $8 \mathrm{~h}$ (mRNA was detected with each $0.5 \mathrm{~h}$ ). Addition of TGF- $\beta 3$ $(10 \mathrm{ng} / \mathrm{ml})$ can significantly downregulate the expression of Smad3 mRNA and upregulate the expression of Smad7 mRNA (P<0.01; Fig. 3). After 4 h, treatment with TGF- $33(10 \mathrm{ng} / \mathrm{ml})$ was observed to significantly downregulate the expression of 

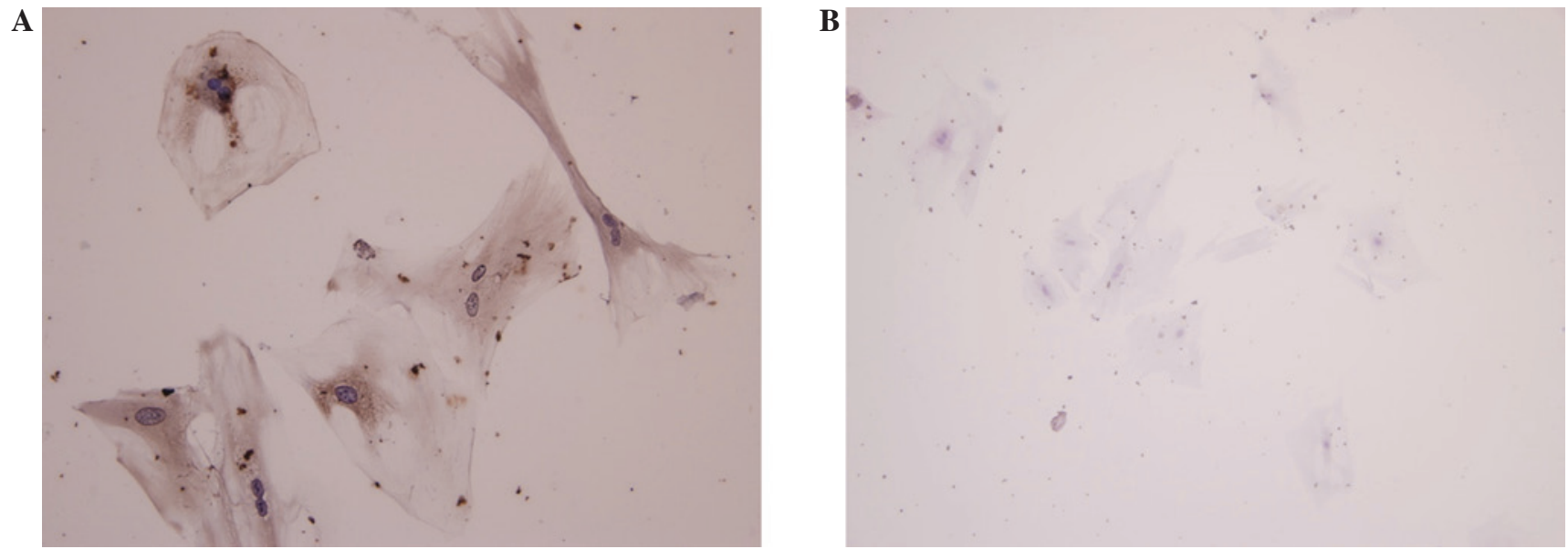

Figure 2. Immunohistochemical assessment. (A) Collagen I positively stained cells. (B) Collagen II megatively stained cells. Magnification x200.
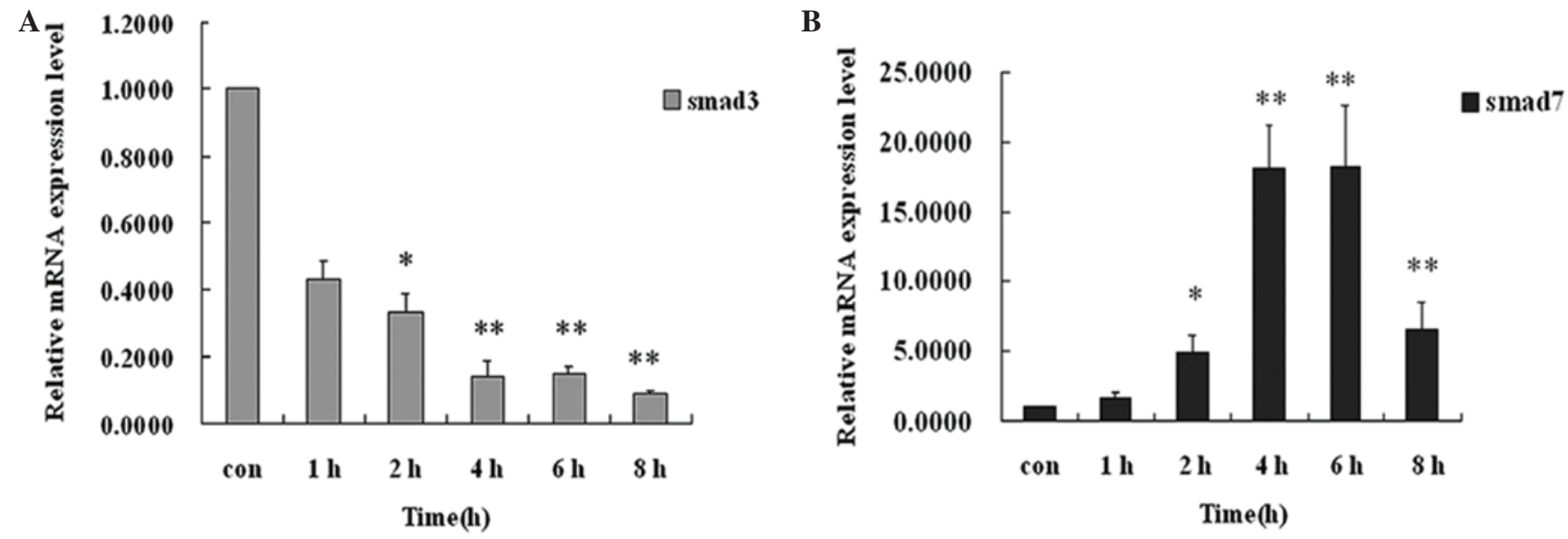

Figure 3. Reverse transcription-quantitative polymerase chain reaction was used to demonstrate the levels of (A) Smad3 and (B) Smad7 following the addition of TGF- $\beta 3$ (10 ng/ml) for $0,1,2,4,6$ and $8 \mathrm{~h} .{ }^{*} \mathrm{P}<0.05,{ }^{* * *} \mathrm{P}<0.01$ compared with control. TGF, transforming growth factor.

phosphorylated and non-phosphorylated Smad3 protein and upregulate the expression of Smad7 protein $(\mathrm{P}<0.01 ;$ Fig. 4).

Addition of CHX and actinomycin D. Addition of CHX inhibited the downregulation of Smad3 protein induced by TGF- $\beta 3$; however, it was not able to block the TGF- $\beta 3$-induced upregulation of Smad7 (Fig. 5). Furthermore, the addition of actinomycin D inhibited the TGF $\beta 3$-induced downregulation of Smad3 protein, and inhibited the TGF 33 -induced upregulation of Smad7 in tenocytes (Fig. 6). The results show that addition of TGF- $\beta 3$ can significantly downregulate the expression of Smad3 protein and upregulate the expression of Smad7 protein. The addition of CHX was shown to inhibit the downregulation of Smad3 mRNA and protein expression in tenocytes $(\mathrm{P}<0.01$; Fig. 7), but not affect Smad7 mRNA or protein expression (Fig. 7).

\section{Discussion}

The postoperative outcome of injured flexor tendon healing remains limited by tendon adhesion. Despite improvements in materials and surgical technique, various pharmacological modalities and the evolution of rehabilitative therapies, tendon adhesion remains one of the most unpredictable results of flexor tendon injury. In particular, peritendinous adhesion formation continues to present a problem. The aims of tendon healing after repair are to promote intrinsic tendon healing and to optimize the tendon range of motion (16). In recent years, studies have shown TGF- $\beta$ s is regulated after tendon injury (17-19). Addition of TGF- $\beta 3$ induces tenogenic differentiation of in vitro cultures of mesenchymal stem cells $(20,21)$, equine embryo-derived stem cells (17) and micro mass cultures of undifferentiated limb mesenchyme (22). This suggests that TGF- $\beta$ signaling is important in triggering the initiation of tenocyte differentiation from tendon progenitors. Although the role of TGF- $\beta$ in fibrosis has been determined, little is known regarding the circulating levels of this cytokine in the injured tendon. In addition, the role of the TGF- $\beta / \mathrm{Smad}$ signaling pathway in tenocyte differentiation remains largely unknown.

TGF- $\beta 3$, an isoform of the TGF- $\beta$ superfamily, initiates cellular actions by binding to specific cell-surface receptor complexes typically composed of TGF- $\beta$ type I (T $\beta R I)$ and II receptors. Binding of TGF- $\beta$ to T $\beta$ RII activates the intrinsic 
A

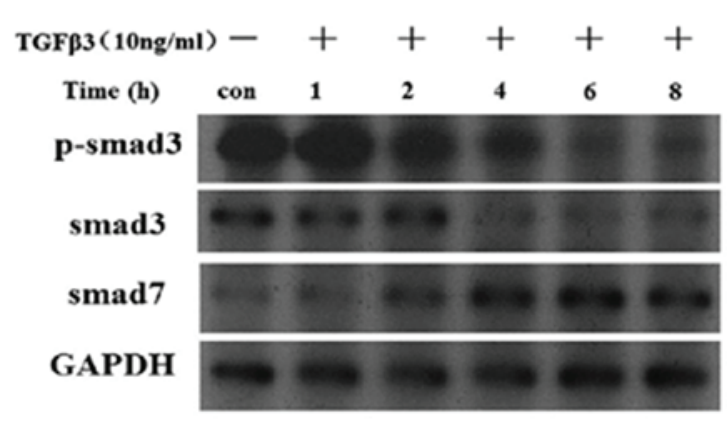

C

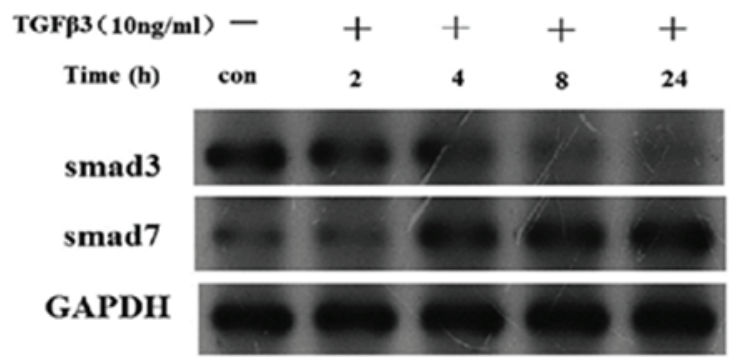

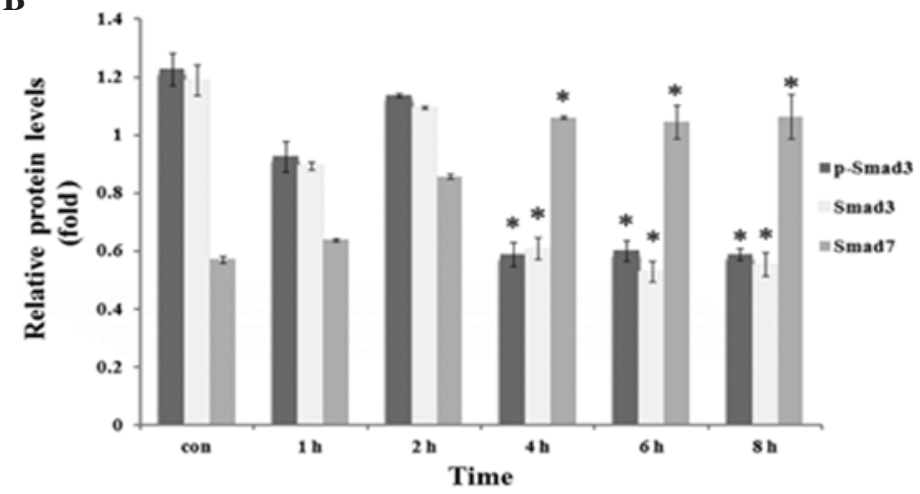

D

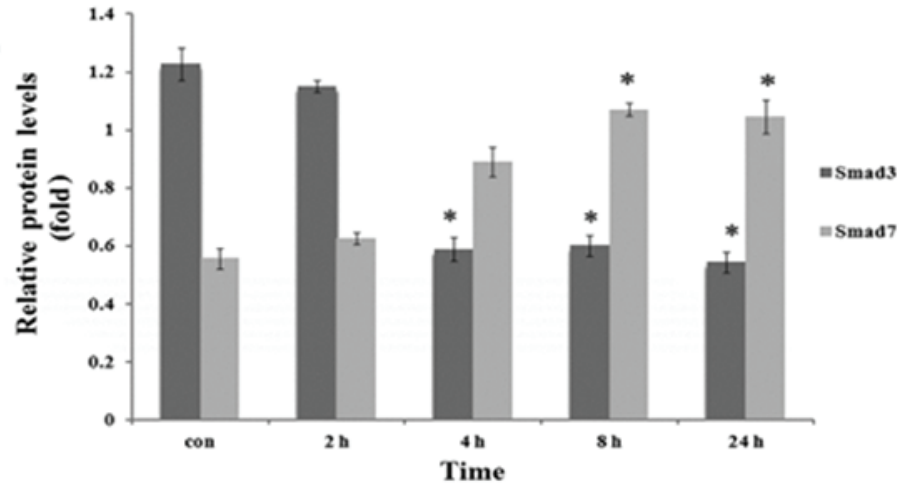

Figure 4. Effect of TGF- $\beta 3$ on the protein expression of Smad3 and Smad7 in tenocytes using western blotting and quantification. (A and B) Protein expression of phosphorylated-Smad3, Smad3 or Smad7 at 1, 2, 4, 6 and $8 \mathrm{~h}$. (C and D) Protein expression of Smad3 or Smad7 at 2, 4, 8 and 24 h. Four hours after the addition of TGF- $33(10 \mathrm{ng} / \mathrm{ml})$ the expression of phosphorylated and non-phosphorylated Smad3 protein was significantly downregulated and the expression of Smad7 protein was significantly upregulated. "P<0.05. TGF, transforming growth factor; GAPDH, glyceraldehyde 3-phosphate dehydrogenase.
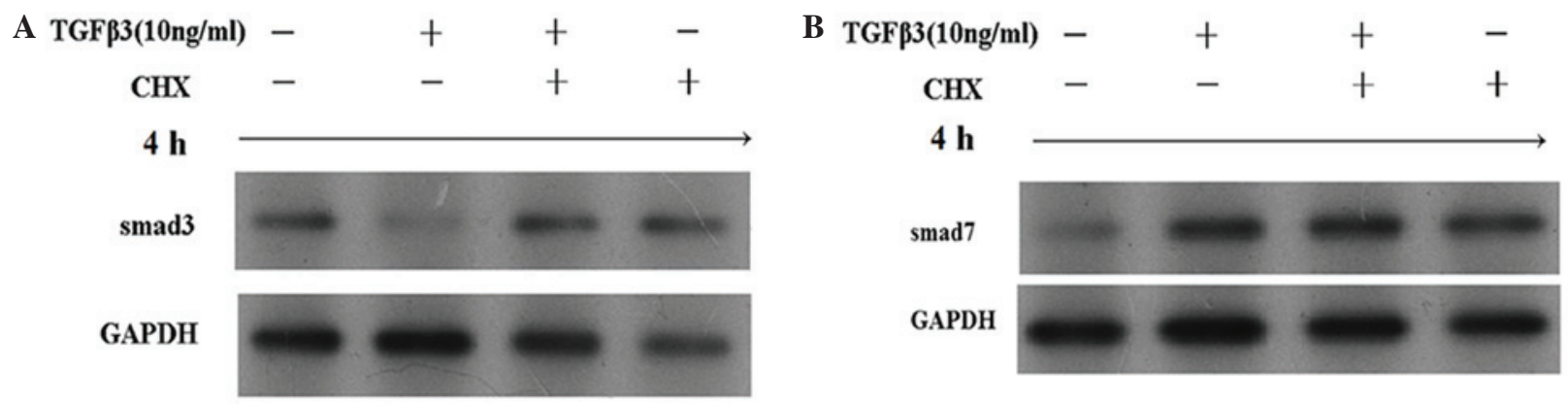

Figure 5. Effect of CHX on the protein expression of Smad3 and Smad7 induced by TGF- $\beta 3$ for $4 \mathrm{~h}$ in tenocytes using western blotting. Protein expression of (A) Smad3 and (B) Smad7 at 4 h. TGF, transforming growth factor; GAPDH, glyceraldehyde 3-phosphate dehydrogenase; CHX, cyclohexamide.

serine/threonine kinase activity of T $\beta R I$, which phosphorylates transcription factors Smad2 and Smad3. p-Smad2 or p-Smad3 combine with Smad4, then the Smad2/Smad4 and/or Smad3/Smad4 complexes translocate into the nucleus, where they function to regulate the transcription of specific genes that possess TGF- $\beta$ response elements in their promoters $(23,24)$. Smad3 knockout mice have been shown to exhibit reduced collagen levels and decreased scarring, as well as increased MMP9 gene and protein expression (7). TGF- $\beta 3$ is antagonized by Smad7, which interacts stably with T $\beta$ RI to prevent phosphorylation and activation of receptor-regulated Smad2/3, therefore inhibiting TGF- $\beta$ signaling (25).

Previous studies have established a role for TGF- $\beta$ signaling in tendon healing by demonstrating that inhibition of neutralization of TGF- $\beta 1$ and $\beta 2$, or the addition of TGF- $\beta 3$ can decrease adhesion formation $(8,26,27)$. A novel TGF- $\beta 3$ controlled-released chitosan scaffold has been developed for tissue engineering of the synovial sheath (28). The present study focused on the effect of TGF- $\beta 3$, and the underlying the TGF- $\beta /$ Smad signaling pathway on wound healing.

In the present study, Smad3 increased collagen levels and decreased MMP9 gene and protein expression. Smad7 inhibited the phosphorylation of receptor Smads via the TGF- $\beta 3$ receptors and prevented the association of receptor Smads with Smad4. If TGF- $\beta 3$ is able to dowregulate the expression of Smad3 protein expression and upregulate the expression of Smad7 protein, it may be used to promote intrinsic tendon healing and reduce adhesion. RT-qPCR and western blot analysis revealed that TGF- $\beta 3$ downregulated the expression of Smad3 mRNA and upregulated the expression of Smad7 


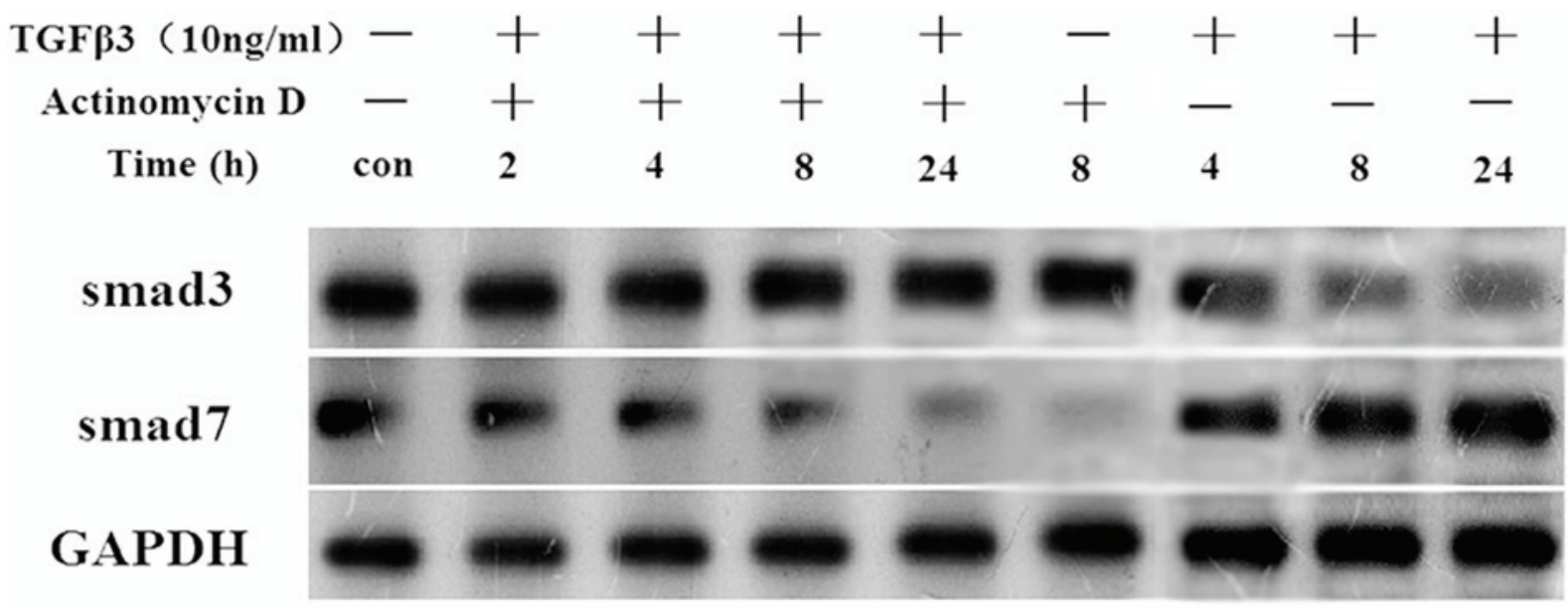

Figure 6. Effect of actinomycin D on the protein expression of Smad3 and Smad7 induced by TGF $\beta 3$ in tenocytes using western blotting. TGF, transforming growth factor; GAPDH, glyceraldehyde 3-phosphate dehydrogenase.

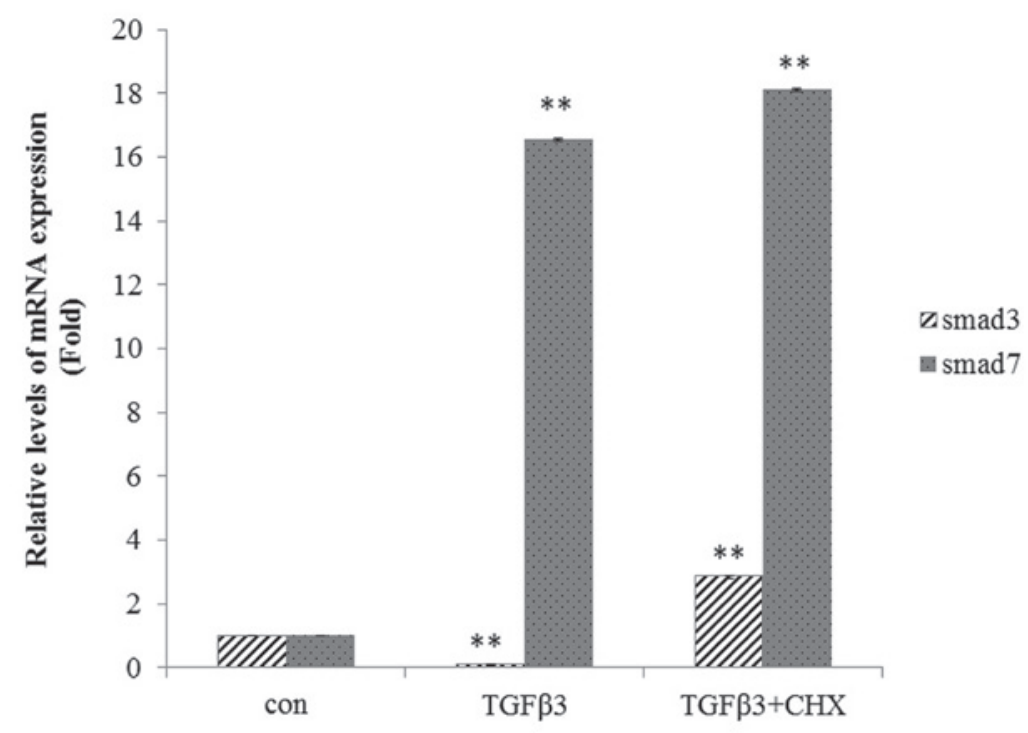

Figure 7. Effect of CHX on the mRNA expression of Smad 3 and Smad7 induced by TGF- $\beta 3$ in tenocytes using reverse transcription-quantitative polymerase chain reaction. "* $\mathrm{P}<0.01$, compared with control. TGF, transforming growth factor; $\mathrm{CHX}$, cyclohexamide.

mRNA. Adding CHX and actinomycin D demonstrated that TGF- $\beta 3$ can significantly downregulate the expression of Smad3 protein and upregulate the expression of Smad7 protein. These results supported the above speculation. Thus, the present study provides important information regarding the specific role of the canonical TGF- $\beta$ signaling pathway in the process of reducing adhesion formation. The results revealed that adding TGF- $\beta 3$ is an effective way to promote intrinsic tendon healing, and result in optimized a tendons range of motion.

In conclusion, the present study demonstrates that the addition of TGF- $\beta 3$ to tenocytes can significantly downregulate the expression of Smad3, and upregulate the expression of Smad7, at the gene and protein level. The results suggest that TGF- $\beta 3$ may regulate $\mathrm{Smad} 3$ and $\mathrm{Smad} 7$ protein expression through the TGF- $\beta$ /Smad signaling pathway to minimize extrinsic scarring. Thus, it may provide a novel approach to decrease tendon adhesion and promote tendon healing. In vivo studies are required in order to provide further evidence of the potential benefits in clinical practice. In the future, the delivery of TGF- $\beta 3$ may be a novel application in the field of hand flexor tendon surgery.

\section{Acknowledgements}

This study was supported by the National Natural Science Foundation of China (grant no. 81000807).

\section{References}

1. Wong JK, Lui YH, Kapacee Z, Kadler KE, Ferguson MW and McGrouther DA: The cellular biology of flexor tendon adhesion formation: An old problem in a new paradigm. Am J Pathol 175: 1938-1951, 2009.

2. Renstrom P, Woo SL-Y and Arnoczky SP (eds): Tendinopathy: A major medical problem in sport. In: Tendinopathy in Athletes. Blackwell Publishing, Hoboken, NJ, pp1-9, 2007.

3. Cox DA: Transforming growth factor-beta 3. Cell Biol Int 19: 357-371, 1995. 
4. Ferguson MW and O'Kane S: Scar-free healing: From embryonic mechanisms to adult therapeutic intervention. Philos Trans R Soc Lond B Biol Sci 359: 839-850, 2004.

5. Shah M, Foreman DM and Ferguson MW: Neutralisation of TGF-beta1 and TGF-beta2 or exogenous addition of TGF-b3 to cutaneous rat wounds reduces scarring. J Cell Sci 108: 985-1002, 1995.

6. Kuo CK, Petersen BC and Tuan RS: Spatiotemporal protein distribution of TGF-betas, their receptors and extracellular matrix molecules during embryonic tendon development. Dev Dyn 237: 1477-1489, 2008.

7. Katzel EB, Wolenski M, Loiselle AE, Basile P, Flick LM, Langstein HN, Hilton MJ, Awad HA, Hammert WC and O'Keefe RJ: Impact of Smad3 loss of function on scarring and adhesion formation during tendon healing. J Orthop Res 29: 684-693, 2011.

8. Bates SJ, Morrow E, Zhang AY, Pham H, Longaker MT and Chang J: Mannose-6-phosphate, an inhibitor of transforming growth factor-beta, improves range of motion after flexor tendon repair. J Bone Joint Surg Am 88: 2465-2472, 2006.

9. Kretzschmar M and Massagué J: Smads: Mediators and regulators of TGF-beta signaling. Curr Opin Genet Dev 8: 103-111, 1998.

10. Derynck $R$ and Zhang YE: Smad-dependent and Smad-independent pathways in TGF-beta family signalling. Nature 425: 577-584, 2003.

11. Brown KA, Pietenpol JA and Moses HL: A tale of two proteins: Differential roles and regulation of Smad2 and Smad3 in TGF-beta signaling. J Cell Biochem 101: 9-33, 2007.

12. Moustakas A, Pardali K, Gaal A and Heldin CH: Mechanisms of TGF-beta signaling in regulation of cell growth and differentiation. Immunol Lett 82: 85-91, 2002.

13. Dennler S, Goumans MJ and ten Dijke P: Transforming growth factor beta signal transduction. J Leukoc Biol 71: 731-740, 2002.

14. Arany PR, Flanders KC, Kobayashi T, Kuo CK, Stuelten C, Desai KV, Tuan R, Rennard SI and Roberts AB: Smad3 deficiency alters key structural elements of the extracellular matrix and mechanotransduction of wound closure. Proc Natl Acad Sci USA 103: 9250-9255, 2006.

15. Livak KJ and Schmittgen TD: Analysis of relative gene expression data using real-time quantitative PCR and the 2(-Delta Delta C(T)) method. Methods 25: 402-408, 2001.

16. Elliot D, Barbieri CH, Evans RB, Mass D and Tang JB: IFSSH flexor tendon committee report 2007. J Hand Surg Eur Vol 32: 346-356, 2007.
17. Barsby T and Guest D: Transforming growth factor beta3 promotes tendon differentiation of equine embryo-derived stem cells. Tissue Eng Part A 19: 2156-2165, 2013.

18. Chan KM, Fu SC, Wong YP, Hui WC, Cheuk YC and Wong MW: Expression of transforming growth factor beta isoforms and their roles in tendon healing. Wound Repair Regen 16: 399-407, 2008.

19. Chen CH, Cao Y, Wu YF, Bais AJ, Gao JS and Tang JB: Tendon healing in vivo: Gene expression and production of multiple growth factors in early tendon healing period. J Hand Surg Am 33: 1834-1842, 2008.

20. Kapacee Z, Yeung CY, Lu Y, Crabtree D, Holmes DF and Kadler KE: Synthesis of embryonic tendon-like tissue by human marrow stromal/mesenchymal stem cells requires a three-dimensional environment and transforming growth factor $\beta 3$. Matrix Biol 29: 668-677, 2010.

21. Barsby T, Bavin EP and Guest DJ: Three-dimensional culture and transforming growth factor beta3 synergistically promote tenogenic differentiation of equine embryo-derived stem cells. Tissue Eng Part A 20: 2604-2613, 2014.

22. Lorda-Diez CI, Montero JA, Martinez-Cue C, Garcia-Porrero JA and Hurle JM: Transforming growth factors beta coordinate cartilage and tendon differentiation in the developing limb mesenchyme. J Biol Chem 284: 29988-29986, 2009.

23. Wrana JL, Attisano L, Wieser R, Ventura F and Massagué J: Mechanism of activation of the TGF-beta receptor. Nature 370: 341-347, 1994

24. Finnson KW, McLean S, Di Guglielmo GM and Philip A: Dynamics of transforming growth factor beta signaling in wound healing and scarring. Adv Wound Care (New Rochelle) 2: 195-214, 2013.

25. Wang W, Huang XR, Li AG, Liu F, Li JH, Truong LD, Wang XJ and Lan HY: Signaling mechanism of TGF-beta1 in prevention of renal inflammation: Role of Smad7. J Am Soc Nephrol 16: 1371-1383, 2005.

26. Chang J, Thunder R, Most D, Longaker MT and Lineaweaver WC: Studies in flexor tendon wound healing: Neutralizing antibody to TGF-beta1 increases postoperative range of motion. Plast Reconstr Surg 105: 148-155, 2000 .

27. Jorgensen HG, McLellan SD, Crossan JF and Curtis AS: Neutralisation of TGF beta or binding of VLA-4 to fibronectin prevents rat tendon adhesion following transection. Cytokine 30: 195-202, 2005.

28. Jiang K, Wang Z, Du Q, Yu J, Wang A and Xiong Y: A new TGF- $\beta 3$ controlled released chitosan scaffold for tissue engineering synovial sheath. J Biomed Mater Res A 102: 801-807, 2014. 